2016-12-13

\title{
EMpowerment of PArents in THe Intensive Care Questionnaire
}

\section{Wolfler, A}

http://hdl.handle.net/10026.1/8271

10.1097/PCC.0000000000001031

Pediatric Critical Care Medicine

Ovid Technologies (Wolters Kluwer Health)

All content in PEARL is protected by copyright law. Author manuscripts are made available in accordance with publisher policies. Please cite only the published version using the details provided on the item record or document. In the absence of an open licence (e.g. Creative Commons), permissions for further reuse of content should be sought from the publisher or author. 
EMpowerment of PArents in THe Intensive Care (EMPATHIC) questionnaire: Translation and Validation in Italian PICUs

Andrea Wolfler $^{1} \mathrm{MD}$, Alberto Giannini ${ }^{2} \mathrm{MD}$, Martina Finestrella ${ }^{1}$, Ida Salvo ${ }^{1} \mathrm{MD}$, Edoardo Calderini $^{2}$ MD, Giulia Frasson ${ }^{3}$, Immacolata Dall'Oglio ${ }^{4} \mathrm{RN}$, Michela Di Furia ${ }^{5}$, Rossella Iuzzolino $^{6}$, Massimo Musicco ${ }^{7}$, Jos M. Latour, PhD, RN, FEfCCNa $^{8,9}$

Pediatric Critical Care Medicine

Accepted: 21 October 2016

Online ahead of print: 15 December 2016; DOI: 10.1097/PCC.0000000000001031

Website:

http://journals.lww.com/pccmjournal/Abstract/publishahead/EMpowerment_of_PArents_in_THe_I ntensive_Care.98720.aspx

1 Department of Anesthesia and Intensive Care, Children's Hospital V Buzzi - Istituti Clinici di Perfezionamento Milan, Italy

2 Pediatric Intensive Care Unit, Fondazione IRCCS Ca' Granda - Ospedale Maggiore Policlinico, Milan, Italy

3 Child and Adolescent Neuropsychiatric Unit, Fondazione IRCCS Ca' Granda - Ospedale Maggiore Policlinico, Milan, Italy

4 Professional Development Continuing Education, and Nursing Research Service - Medical Direction, Children's Hospital Bambino Gesù, IRCCS Rome, Italy

5 Department of Anesthesia and Intensive Care, Children's Hospital Bambino Gesù, IRCCS Rome, Italy

6 Department of Pediatric Medical Surgical Cardiology, Children's Hospital Bambino Gesù, IRCCS Rome, Italy

7 Institute of Biomedical Technologies, National Research Council, Milan, Italy

8 School of Nursing and Midwifery, Faculty of Health and Human Sciences, Plymouth University, Plymouth, United Kingdom

9 School of Nursing, Midwifery and Paramedicine, Faculty of Human Science, Curtin University, Perth, Australia

\section{Corresponding author:}

Andrea Wolfler, MD

Department of Anesthesia and Intensive Care Unit

Children's Hospital Vittore Buzzi

ASST Fatebenefratelli Sacco

Via Castelvetro 32

20152 Milan, Italy

Tel. +39-02-57995335

Fax +39-02-57995178

Email: andrea.wolfler@asst-fbf-sacco.it

Conflict of Interest: The authors have not disclosed any potential conflicts of interest.

Keywords: Pediatric Intensive Care; Satisfaction; Parents; Surveys and Questionnaires; Evaluation 
Abstract

Objective: To translate and validate the EMpowerment of PArents in THe Intensive Care (EMPATHIC) questionnaire to measure parent satisfaction and experiences in Italian Pediatric Intensive Care Units (PICUs).

Design: Prospective, multicenter study.

Setting: Four medical/surgical Italian PICUs in three tertiary hospitals.

Patients: Families of children, 0-16 year of age, admitted to the PICUs were invited to participate. Inclusion criteria were: PICU length-of-stay $>24$ hours, good comprehension of Italian language by parents/guardians. Exclusion criteria were readmission within 6 months and parents of a child who died in the PICU.

Intervention: Distribution, at PICU discharge, of the EMPATHIC questionnaire with 65-items divided in five domains and a 6-point rating scale; 1 'certainly no' to 6 'certainly yes'.

Measurements and main results: Back and forward translations of the EMPATHIC questionnaire between Dutch (original version) and Italian languages were deployed. Cultural adaptation of the instrument was confirmed by a consultation with a representative parent group $(n=10)$. Totally, $150 / 190(79 \%)$ parents participated in the study. On item level, 12 statements scored a mean below 5.0. The Cronbach alpha, measured for internal consistency, on domain level was between 0.67 and 0.96. Congruent validity was measured by correlating the five domains with four gold standard satisfaction measures and showed adequate correlations ( $r_{\mathrm{s}}$ 0.41-0.71, $\left.\mathrm{p}<0.05\right)$. No significant differences occurred in the non-differential validity testing between three children's characteristics and the domains; excepting parents with a child for a surgical and planned admission were more satisfied on information and organization issues.

Conclusions: The Italian version of the EMPATHIC questionnaire has satisfactory reliability and validity estimates and seems to be appropriate for Italian PICU setting. It is an important instrument providing benchmark data to be used in the process of quality improvement toward the development of a family-centered care philosophy within Italian PICUs. 


\section{INTRODUCTION}

Partnership in care between doctors, nurses, patients and their families should be a standard in daily practice in Pediatric Intensive Care Unit (PICU) settings. In order to increase the effectiveness of such an alliance, patient and family satisfaction outcomes have been promoted and are currently a recognized quality performance indicator $(1,2)$. In the PICU the patient is a child and the stakeholders for clinicians are the parents. Therefore, the family-centered care approach is important to deliver care to the child and family while recognizing the needs and experiences of the family $(3,4)$. The philosophy is defined in the approach that parents are integral parts within the healthcare team while working in partnership in the PICU $(5,6)$. Family-centered care is expected to improve the quality and safety of a patient's care by fostering communication between parents and healthcare professionals (7). This perspective is even more important in a PICU where clinical status, clinical decisions, and complex, invasive and life sustaining interventions make the hospitalization experience unique.

One of the emerging trends in healthcare is the inclusion of patient/family perspectives in developing quality performance indicators (8-10). Nevertheless, until a few years ago we did not have specific validated instruments in PICU settings. A recent developed and tested instrument specifically for the PICU population is the EMpowerment of PArents in The Intensive Care (EMPATHIC) questionnaires (11). The EMPATHIC questionnaire evaluates the experiences and satisfaction of parents in the PICU. This 65-item instrument examines different domains of PICU care and treatment, such as information, care and treatment, attitude of clinicians, and parental participation, and allows us to develop awareness of our ability to collaborate with parents based on their experiences. In recent years, the Italian PICUs have made progress in increasing the level of parental participation. For example, progress has been documented in visiting policies in Italian PICUs (12,13). Despite this progress, limited evidence is available on the overall family-centered care support in Italian PICUs and the evaluation of the parents experience. Unfortunately, no instrument exists measuring the experiences and satisfaction of parents in Italian PICU settings, making it difficult to initiate or compare any quality improvement initiative. The aim of this study is to translate and to validate the original Dutch EMPATHIC questionnaire for Italian PICUs.

\section{MATERIALS AND METHODS}

\section{Translation process}

The study was organized in two parts: 1) translation of the instrument, 2) validation of the translated instrument. The original EMPATHIC questionnaires was developed in the Netherlands in eight PICUs via a cohort of studies (11,14-16). Confirmatory factor analysis provided a structure of 65 statements divided in five domains: information, care and cure, organization, parental participation, 
and professional attitude (8). The reliability and validity was adequately tested with Cronbach's alpha estimates between $0.73-0.93$ on domain level. Validity was confirmed by a good correlation between the domains and four standard satisfaction measures as well as sufficient non-differential validity.

Translation of the questionnaire was organized through a structured method to ensure accuracy and reliability (17). This method consisted in a 10-step process and included forward (Dutch - Italian) and backward (Italian - Dutch) translations by two different native speakers, followed by testing the instrument for cognitive equivalence with 10 parents (Table 1). Minor changes were made based on the comments of the parents, such as changing the wording in a statement using 'not equivocal'. Debriefing among researchers (including the author of the original instrument) took place during the process to solve concerns during the translation process.

Table 1: Translation process

\begin{tabular}{|c|c|}
\hline Translation steps & Actions \\
\hline Step 1: Preparation & $\begin{array}{l}\text { 1.1 Request from the study promoter to the developer of the questionnaire to } \\
\text { translate and use the instrument } \\
\text { 1.2 Involvement of the developer of the questionnaire in the translation process } \\
\text { 1.3 The study promoter and the developer produced conceptual basis for the } \\
\text { translation }\end{array}$ \\
\hline Step 2: Dutch-Italian translation & $\begin{array}{l}\text { 2.1 The study promoter and the translators received information about the } \\
\text { questionnaire } \\
\text { 2.2 Two independent translators translated from Dutch to Italian }\end{array}$ \\
\hline Step 3: Reconciliation & 3.0 Comparison with the developer and comparison between the translations \\
\hline Step 4: Italian Dutch Translation & 4.0 Back translation Italian-to-Dutch \\
\hline Step 5: Back translation revision & $\begin{array}{l}\text { 5.0 The developer of the questionnaire helped the study promoter to solve } \\
\text { concerns about translations }\end{array}$ \\
\hline Step 6: Harmonization & $\begin{array}{l}\text { 6.0 Harmonization of the translated version through a meeting between } \\
\text { developer and promoter }\end{array}$ \\
\hline Step 7: Cognitive debriefing & $\begin{array}{l}\text { 7.0 The translated instrument was tested by } 10 \text { parents to evaluate } \\
\text { comprehension. The developer visited the centers that participate in the study }\end{array}$ \\
\hline $\begin{array}{l}\text { Step 8: Revision of cognitive } \\
\text { debriefing and finalization }\end{array}$ & $\begin{array}{l}\text { 8.1 If needed identify modification of the translation to improve comprehension } \\
\text { 8.2 Sharing changes between promoter and developer of the study }\end{array}$ \\
\hline Step 9: Test editing & 9.0 Test editing for grammar and typing errors \\
\hline Step 10: Final report & 10.0 Final written report which include the used method description \\
\hline
\end{tabular}

\section{Settings}

After the translation process, the Italian version of the EMPATHIC questionnaire was tested in four PICUs located in three tertiary hospitals. Three PICUs were medical/surgical units with six/eight beds and over 400 admissions per year and the fourth participating unit was a cardiac PICU with 12 beds and about 500 admissions per year. One unit was located in the pediatric department of a general hospital while the other three were located in pediatric hospitals.

Approval of the study was granted by the Ethical Committee (EC) of Children's Hospital Vittore Buzzi, the coordinating center of the study and then by the ECs of the other two hospitals. A 
signed informed consent was required for the study. Participation was voluntary and all questionnaires were anonymous.

\section{Participants}

Study participants were parents of children admitted to a PICU. Inclusion criteria were: PICU length-of-stay $(\mathrm{LOS})>24$ hours and good comprehension of the Italian language by parents or legal guardians. The level of Italian language was assessed during admission when communicating with parents. If parents would need an interpreter to communicate they were excluded from the study. Exclusion criteria were parents whose child died in the PICU and PICU readmission within six months. Questionnaires were handed over to the parents by the nurses the day before discharge or at discharge. One PICU started to mail the questionnaires to the parents' home after hospital discharge. This resulted in a small number of responses and delivery was changed to handing over the questionnaire at PICU discharge.

Parents were able to return the questionnaire in a separate box on the PICU or by post. Each questionnaire had a unique identification code linked to the child. Only the principal investigator of each PICU was allowed to recognize the code in order to send one reminder after three weeks if no response was received. Data collection was between January and June 2015.

\section{Statistical analysis}

Data analysis have been performed with NCSS statistical software (NCSS 9.0,LLC - Utah, USA). Descriptive statistics and non-parametric tests of difference have been applied. Significance was set at $p<0.05$. Means and standard deviations have been calculated to determine the outcome of the satisfaction items. Reliability was assessed using Cronbach's alpha to confirm internal consistency of the statements within the domains of the instrument. A Cronbach's alpha of $>0.70$ represents reasonable to satisfactory reliability estimates. Spearman's Rank correlation to estimate the relationship between domains and four general satisfaction questions was used to confirm congruent validity. The four satisfaction questions were related to: suggesting the PICU to others, coming back again if needed, overall satisfaction of physicians, and overall satisfaction of nurses. These general satisfaction questions have been used by industry and healthcare organizations such as the Friends and family test by the National Health Services (NHS) in the UK. Non-differential validity refers to variables assuming to have non-differential statistical effects. This was measured by Cohen's d (effect size of standardized mean differences) between domains and three descriptors: planned/unplanned admission, surgical/medical admission and use of mechanical ventilation (MV) during PICU stay. 


\section{RESULTS}

Overall, 190 parents received the questionnaire and 150 (78.9\%) responded; range in the four PICUs was $60-98 \%$. Parents were enrolled at the same rate in the three hospitals. Parents' and children's characteristics are presented in Table 2. Mothers were the most frequent parent who answered the questionnaires $(53.6 \%)$ while only $24.5 \%$ of the questionnaires were completed by fathers.

Table 2: Characteristics of parents and children

\begin{tabular}{lrr}
\hline Characteristic & Who completed the questionnaire: \\
Mother & $53.6 \%(81)$ \\
& Father & $24.5 \%(37)$ \\
Both & $19.2 \%(29)$ \\
\hline Ethnicity: & Italian & $94.7 \%(142)$ \\
& European & $2.6 \%(4)$ \\
& Mixed & $2.0 \%(3)$ \\
Child Age, years & Mean (range) & $6(0-20)$ \\
& Median (IQR) & $3(0-12)$ \\
PICU LOS, days & Mean (range) & $6.2(1-44)$ \\
& Median (IQR) & $4(2-7)$ \\
Admission: & Unplanned & $48.6 \%(73)$ \\
& Planned & $51.3 \%(77)$ \\
\hline Typology: & Surgical & $50.7 \%(76)$ \\
& Medical & $49.3 \%(74)$ \\
\hline Mechanical ventilation: & Yes & $70.0 \%(105)$ \\
& No & $30.0 \%(45)$ \\
\hline Legend: LOS = length of stay, PICU = pediatric intensive care unit
\end{tabular}

Mean score and standard deviation (SD) of the individual statements are presented in Table 3 and are ranked per domain on the highest mean score. Most of the 65 items performed well, 15 answers (23\%) showed a mean value less or equal than 5.0: six in the Parental Participation (PP) domain, four in Information, two in Care and Cure $(\mathrm{C} \& C)$ and Organization domains each and one in the Professional Attitude (PA) domain. All the items achieved a similar score among the three centers $(p=0.38)$. 
Table 3: Cronbach alpha for each domain in the overall cohort and for each center tested

\begin{tabular}{l|cccc} 
Domain & $\begin{array}{c}\text { Cronbach's alpha } \\
\text { overall }\end{array}$ & $\begin{array}{c}\text { Cronbach's alpha } \\
\text { center \# 1 }\end{array}$ & $\begin{array}{c}\text { Cronbach's alpha } \\
\text { center \# 2 }\end{array}$ & $\begin{array}{c}\text { Cronbach's alpha } \\
\text { center \# 3 }\end{array}$ \\
\hline Care \& cure & 0.95 & 0.96 & 0.86 & 0.96 \\
Information & 0.90 & 0.84 & 0.95 & 0.80 \\
Organization & 0.67 & 0.69 & 0.59 & 0.60 \\
Professional attitude & 0.85 & 0.94 & 0.91 & 0.89 \\
Parental participation & 0.92 & 0.77 & 0.88 & 0.81 \\
\hline
\end{tabular}

The Cronbach's alpha values on domain level were between 0.67 and 0.92 . Table 4 presents the alpha value for each domain in the entire study group and for each participating center. Only one domain, Organization, showed an alpha value less than 0.70 .

Table 4: descriptive analysis for each statement ranked per domain on the highest mean

\begin{tabular}{|c|c|c|c|}
\hline Domain and Statements & Mean & SD & $\begin{array}{l}\text { Cronbach's } \alpha \\
\text { if item deleted }\end{array}$ \\
\hline \multicolumn{4}{|l|}{ Domain Care \& Cure } \\
\hline The doctors and nurses are real professionals; they know what they are doing & 5.8 & 0.46 & 0.95 \\
\hline During acute situations there was always a nurse to support us & 5.8 & 0.52 & 0.95 \\
\hline The team was helpful to our child and to us & 5.7 & 0.59 & 0.95 \\
\hline When our child's condition worsened, action was immediately taken by the nurses & 5.7 & 0.51 & 0.95 \\
\hline The team had a common goal: the best care and treatment for our child and ourselves & 5.7 & 0.72 & 0.95 \\
\hline Attention was paid to our child's developmental level by the doctors & 5.7 & 0.65 & 0.94 \\
\hline Our child's comfort was taken into account by the nurses & 5.7 & 0.52 & 0.95 \\
\hline The doctors and nurses worked closely together & 5.7 & 0.62 & 0.95 \\
\hline Attention was paid to our child's developmental level by the nurses & 5.6 & 0.70 & 0.94 \\
\hline Our own needs were well responded to by the doctors & 5.6 & 0.77 & 0.94 \\
\hline When our child's condition worsened, action was immediately taken by the doctors & 5.6 & 0.83 & 0.94 \\
\hline Transferral of care from the PICU staff to colleagues in the pediatric ward had gone well & 5.6 & 0.74 & 0.95 \\
\hline Our child's comfort was taken into account by the doctors & 5.6 & 0.74 & 0.94 \\
\hline The team was alert to the prevention and treatment of pain in our child & 5.6 & 0.92 & 0.95 \\
\hline Our own needs were well responded to by the nurses & 5.5 & 0.78 & 0.94 \\
\hline We were well prepared for our child's admission by the doctors & 5.5 & 0.98 & 0.95 \\
\hline We were well prepared for our child's discharge by the doctors & 5.5 & 0.92 & 0.95 \\
\hline Our child's needs were well responded to by the doctors & 5.4 & 0.84 & 0.94 \\
\hline At admission our child's medical history was known by the doctors & 5.4 & 1.16 & 0.95 \\
\hline The correct medication was always given on time & 5.4 & 1.02 & 0.95 \\
\hline Our child's needs were well responded to by the nurses & 5.3 & 0.91 & 0.94 \\
\hline We were well prepared for our child's discharge by the nurses & 5.3 & 1.11 & 0.94 \\
\hline We were well supported emotionally by the nurses & 5.3 & 1.17 & 0.94 \\
\hline We were well supported emotionally by the doctors & 5.2 & 1.14 & 0.95 \\
\hline During our child's stay we were assigned to one and the same doctor & 5.2 & 1.55 & 0.95 \\
\hline At admission our child's medical history was known by the nurses & 5.1 & 1.28 & 0.95 \\
\hline Every day we knew who was responsible for our child, regarding the nurses & 5.1 & 1.30 & 0.94 \\
\hline During our child's stay we were assigned to a first responsible nurse & 5.1 & 1.59 & 0.95 \\
\hline Every day we knew who was responsible for our child, regarding the doctors & 5.0 & 1.30 & 0.95 \\
\hline We were well prepared for our child's admission by the nurses & 4.8 & 1.65 & 0.95 \\
\hline \multicolumn{4}{|l|}{ Domain Information } \\
\hline We received clear information about the examinations and tests & 5.5 & 0.85 & 0.89 \\
\hline We were given clear information about our child's disease & 5.4 & 0.83 & 0.90 \\
\hline The doctor clearly informed us about the consequences of our child's treatment & 5.4 & 0.87 & 0.89 \\
\hline We were always informed right away when our child's physical condition worsened & 5.4 & 0.92 & 0.89 \\
\hline Our questions were clearly answered by the doctors & 5.3 & 0.94 & 0.89 \\
\hline We had daily talks about our child's care and treatment with the doctors & 5.0 & 1.36 & 0.89 \\
\hline Our questions were clearly answered by the nurses & 5.0 & 1.23 & 0.89 \\
\hline We received understandable information about the effects of the drugs & 4.9 & 1.32 & 0.90 \\
\hline We had daily talks about our child's care and treatment with the nurses & 4.7 & 1.58 & 0.90 \\
\hline \multicolumn{4}{|l|}{ Domain Organization } \\
\hline The PICU could easily be reached by telephone & 5.7 & 0.77 & 0.67 \\
\hline The PICU was clean & 5.6 & 0.75 & 0.65 \\
\hline The team worked efficiently & 5.6 & 0.71 & 0.61 \\
\hline There was enough space around our child's bed & 5.4 & 0.95 & 0.62 \\
\hline Noise in the PICU was muffled as well as possible & 4.9 & 1.48 & 0.55 \\
\hline The visiting hours were flexible & 4.6 & 1.78 & 0.62 \\
\hline \multicolumn{4}{|l|}{ Domain Professional Attitude } \\
\hline Our child's health always came first for the doctors & 5.7 & 0.66 & 0.92 \\
\hline The team showed respect for our child and for us & 5.6 & 0.92 & 0.91 \\
\hline
\end{tabular}




\begin{tabular}{|c|c|c|c|}
\hline At admission we felt welcome & 5.6 & 0.85 & 0.92 \\
\hline Our child's health always came first for the nurses & 5.6 & 0.80 & 0.91 \\
\hline We received sympathy from the nurses & 5.5 & 0.87 & 0.91 \\
\hline We received sympathy from the doctors & 5.5 & 0.78 & 0.91 \\
\hline The team worked hygienically & 5.5 & 0.97 & 0.91 \\
\hline In spite of the workload, sufficient attention was paid to our child and to us by the nurses & 5.4 & 0.89 & 0.91 \\
\hline The team respected the privacy of our child and of us & 5.4 & 0.88 & 0.91 \\
\hline There was a pleasant atmosphere among the staff & 5.3 & 1.09 & 0.91 \\
\hline In spite of the workload, sufficient attention was paid to our child and to us by the doctors & 5.2 & 0.98 & 0.91 \\
\hline Nurses and doctors always introduced themselves by name and function & 4.0 & 1.76 & 0.93 \\
\hline \multicolumn{4}{|l|}{ Domain Parental Participation } \\
\hline We had confidence in the doctors & 5.7 & 0.66 & 0.84 \\
\hline We had confidence in the nurses & 5.5 & 0.84 & 0.84 \\
\hline Before discharge the care for our child was once more discussed with us by the doctors & 4.9 & 1.52 & 0.83 \\
\hline We were encouraged to stay close to our child & 4.9 & 1.39 & 0.82 \\
\hline We were actively involved in decision-making on care and treatment of our child & 4.8 & 1.37 & 0.82 \\
\hline Before discharge the care for our child was once more discussed with us by the nurses & 4.4 & 1.82 & 0.81 \\
\hline During our stay the staff regularly asked for our experiences & 3.7 & 1.92 & 0.81 \\
\hline Even during intensive procedures we could always stay close to our child & 3.3 & 2.07 & 0.85 \\
\hline
\end{tabular}

Legend: $\mathrm{SD}=$ standard deviation, $\mathrm{C} \& \mathrm{C}=$ care and cure, $\mathrm{INF}=$ information, $\mathrm{ORG}=$ organization, $\mathrm{PA}=$ professional attitude, $\mathrm{PP}=$ parental participation

The EMPATHIC questionnaire showed good correlation with the four general satisfaction questions and confirms adequate congruent validity (Table 5). Mean values of the gold standards 'PICU suggestion to others' and 'come back again if needed' were $5.7( \pm 0.64)$ and $5.7( \pm 0.57)$ respectively. The overall satisfactions measures for physicians and nurses (answer scale was 1 extremely poor to 10 excellent) were $9.1( \pm 1.1)$ and $8.9( \pm 1.2)$ respectively $(p=0.13)$. When comparing the mean score in each domain between the three child's characteristics, we found statistical significance within some domain for type of admission (planned vs unplanned and surgical vs medical) while the use of mechanical ventilation during PICU stay did not show any difference in the family judgment (Table 6). The size effect, measured with the Cohen's d, was always less than 0.3 .

Table 5: correlation among domains and general questions

\begin{tabular}{l|cccc} 
& $\begin{array}{c}\text { Would suggest } \\
\text { PICU to others }\end{array}$ & $\begin{array}{c}\text { Would come back } \\
\text { again if needed }\end{array}$ & $\begin{array}{c}\text { Overall satisfaction } \\
\text { with physicians }\end{array}$ & $\begin{array}{c}\text { Overall satisfaction } \\
\text { with nurses }\end{array}$ \\
\hline Care and cure & 0.63 & 0.66 & 0.50 & 0.67 \\
Information & 0.60 & 0.65 & 0.44 & 0.57 \\
Organization & 0.41 & 0.46 & 0.47 & 0.51 \\
Professional attitude & 0.58 & 0.66 & 0.53 & 0.73 \\
Parental participation & 0.50 & 0.53 & 0.45 & 0.59 \\
\hline
\end{tabular}

Correlation is significant at 0.01 (two-tailed) 
Table 6: non differential analysis of each domain and characteristics: type of admission (planned vs unplanned, medical vs surgical) and use of MV during PICU stay

\begin{tabular}{|c|c|c|c|c|c|c|c|c|c|}
\hline & \multicolumn{3}{|c|}{ Planned } & \multicolumn{3}{|c|}{ Unplanned } & \multirow[b]{2}{*}{$p$} & \multirow[b]{2}{*}{$\begin{array}{c}\text { Mean } \\
\text { difference }\end{array}$} & \multirow[b]{2}{*}{$\begin{array}{c}\text { Size } \\
\text { effect }\end{array}$} \\
\hline & $n$ & Mean & SD & $n$ & Mean & SD & & & \\
\hline$C \& C$ & 77 & 4.95 & 0.95 & 73 & 4.86 & 1.04 & 0.571 & 0.093 & 0.047 \\
\hline INF & 77 & 5.17 & 0.84 & 73 & 4.81 & 1.22 & $0.043^{*}$ & 0.355 & 0.17 \\
\hline Org & 77 & 5.36 & 0.55 & 73 & 4.98 & 0.8 & $0.001 *$ & 0.383 & 0.28 \\
\hline PA & 77 & 5.35 & 0.7 & 73 & 5.11 & 0.88 & 0.066 & 0.244 & 0.15 \\
\hline \multirow[t]{3}{*}{$\mathbf{P P}$} & 77 & 4.61 & 0.99 & 73 & 4.39 & 1.16 & 0.21 & 0.224 & 0.10 \\
\hline & \multicolumn{3}{|c|}{ Surgical } & \multicolumn{3}{|c|}{ Medical } & & & \\
\hline & $n$ & Mean & SD & $n$ & Mean & SD & $p$ & $\begin{array}{c}\text { Mean } \\
\text { difference }\end{array}$ & $\begin{array}{l}\text { Size } \\
\text { effect }\end{array}$ \\
\hline $\mathrm{C \& C}$ & 76 & 4.95 & 0.99 & 74 & 4.87 & 0.99 & 0.627 & 0.079 & 0.04 \\
\hline INF & 76 & 5.13 & 0.93 & 74 & 4.85 & 1.14 & 0.106 & 0.279 & 0.13 \\
\hline Org & 76 & 5.34 & 0.58 & 74 & 5.01 & 0.79 & $0.004^{*}$ & 0.329 & 0.24 \\
\hline PA & 76 & 5.36 & 0.69 & 74 & 5.10 & 0.88 & $0.045^{*}$ & 0.263 & 0.17 \\
\hline \multirow[t]{3}{*}{ PP } & 76 & 4.61 & 1.03 & 74 & 4.38 & 1.11 & 0.19 & 0.233 & 0.11 \\
\hline & \multicolumn{3}{|c|}{ MV } & \multicolumn{3}{|c|}{ SB } & & & \\
\hline & $n$ & Mean & SD & $n$ & Mean & SD & $p$ & $\begin{array}{c}\text { Mean } \\
\text { difference }\end{array}$ & $\begin{array}{l}\text { Size } \\
\text { effect }\end{array}$ \\
\hline$C \& C$ & 105 & 4.90 & 1.14 & 45 & 4.93 & 0.94 & 0.872 & -0.032 & -0.01 \\
\hline INF & 105 & 5.03 & 1.06 & 45 & 4.98 & 1.07 & 0.782 & 0.054 & 0.02 \\
\hline Org & 105 & 5.20 & 0.61 & 45 & 5.16 & 0.74 & 0.737 & 0.040 & 0.03 \\
\hline PA & 105 & 5.32 & 0.78 & 45 & 5.21 & 0.82 & 0.439 & 0.114 & 0.07 \\
\hline PP & 105 & 4.37 & 1.14 & 45 & 4.54 & 1.07 & 0.419 & -0.162 & -0.07 \\
\hline
\end{tabular}

Size effect estimated as Cohen's d.

Legend: $\mathrm{C} \& \mathrm{C}=$ care and cure; $\mathrm{Inf}=$ information; $\mathrm{Org}=$ organization; $\mathrm{PA}=$ professional attitude; $\mathrm{PP}=$ parental participation, $\mathrm{MV}=$ mechanical ventilation, $\mathrm{SB}=$ spontaneous breathing

\section{DISCUSSION}

In intensive care settings, validated parent or family satisfaction instruments are available in the literature, but only few describe completely parents' expectations, experiences, and satisfaction aside from measuring stress or anxiety $(18,19)$. The EMPATHIC questionnaire was developed with the aim of bridging this lack for PICU patients and their families. The first aim of our study was to translate the questionnaire from Dutch to Italian. A thorough translation of the instrument was performed to ensure that the meaning of the translated statements corresponds to the original statements (17). In the Netherlands, the author of the EMPATHIC instrument demonstrated that families with a Dutch or non-Dutch cultural background understood the statements in the instrument without significant differences in the results. Nevertheless, validation in different settings and different populations improves the generalizability and diffusion of validated instruments (20). 
Our study showed that this instrument performed well in an Italian setting. The Cronbach's alpha was reasonable in all but one domain and for each PICU that participated in the study, meaning that the correlation of all statements related to a certain construct was good or excellent. The organization domain showed a questionable internal consistency with a value less than 0.7. We observed that the mean values of all the statements in this domain were above 5 and there was not a specific statement that could increase the Cronbach's alpha value. Because the Cronbach's alpha is a measure of the number of items in a test (21), the observed internal consistency in the domain organization was probably affected by the small number of statements compared to the other domains. Furthermore, compared to the original Dutch version of the EMPATHIC questionnaire we observed higher values of the correlation tests reflecting a modest correlation with the four general satisfaction questions.

Evaluation of the relationship between families and PICU staff is a complex topic. On one side there is a family that is caught up in a fragile emotional state, most of the time unexpected, sensitive to everything going on around them (22). On the other side, there is the PICU staff involving different healthcare professionals each with their own interpersonal and relational skills (23). Although all the units in the study are dedicated PICUs, none has specific rules or protocols for communication with parents. The availability of an instrument that can investigate how we deal with the emotions of others and the empathy of our behavior during daily work expands the potential PICU assessment. The results of our study showed a positive evaluation of the parents about the staff attitude in all four PICUs. The correlation between the domains and the four general final questions was good. Two of these investigated the overall evaluation of the units and the remaining two explored specific evaluation of physicians and nurses. The agreement among the variables strengthens the behavior of the questionnaire showed by the value of each domain suggesting that child care and family experience were appropriate.

Although the PICUs are all open units where the parents can spend most of the time near their child, some of the statements revealed that parents were not as involved in their child's care as expected or desired. Overall, the five domains received an excellent score. However, the domain Parental Participation had the lowest overall mean score. Indeed, of the 15 statements out of 65 that received a value less or equal to 5, six were in the PP domain. Two of them accounted for less than 4: "Even during intensive procedures we could always stay close to our child" and "During our stay the staff regularly asked for our experiences". This might be due to the difficulty of explaining to the family all the clinical and therapeutic choices but primarily depends on the fact that all the units do not allow parents to stay near their child during invasive maneuvers such as vascular catheterization, intubation and cardio-pulmonary resuscitation. This practice is probably connected to healthcare staff feeling uncomfortable and misjudged if difficulties arise during the procedure in 
front of the family. However, current European guidelines provide guidance towards more integration of parents during invasive procedure, like cardio-pulmonary resuscitation (24). Moreover, the relationship with the family might be less effective if there is not one person in charge for the daily talks with parents and other relatives, be that either a nurse or physician. Similar to the original EMPATHIC study (11) our results showed that parents of children with planned and postoperative admission were more satisfied about information and organization statement than those with unplanned and medical admissions. This difference, although statistical significant, might have limited clinical impact. This might be explained by the fact that planned surgical admissions have usually a rigorous pre-admission information process for parents that is well explained and understood by the parents before admission (25).

One difference from the Dutch study is the timing of questionnaire delivery. The Dutch study mailed the questionnaire to the parent's home two to three weeks after PICU discharge and the family could mail back the questionnaire via a dedicated envelope. This recruitment strategy achieved a response rate of around 60\% (11). In Italy due to organizational issues the EMPATHIC questionnaire was delivered to parents at PICU discharge and parents could return it either during hospital stay or post it later from home. Our strategy resulted in a response rate up to $90 \%$ in three units and around $70 \%$ in the fourth. A review of 210 patient satisfaction studies revealed that a faceto-face recruitment strategy revealed a significantly higher response rate compared to postal recruitment (26). Therefore, it might be advised to hand over the questionnaire to parents by person. However, the experience in PICU may be reported differently if reconsidered immediately or weeks after discharge. Additionally, we are aware that meanwhile the Dutch EMPATHIC questionnaire has been statically reduced to the EMPATHIC-30 with 30 items (27). Certainly it will be desirable to also validate the short version as this would benefit benchmarking with other PICUs in Europe and other countries of the world. It will possibly also increase the response rate. However, the review of 210 patient satisfaction studies also revealed that response rate was not associated with the length of a questionnaire.

Two study limitations warrant attention. Firstly, our study was conducted in only three hospitals. Therefore we are not representative of all PICUs in Italy. Two of the three hospitals where located in the north and one in the center of Italy. We did not have any unit located in the southern part of Italy. However, the next step is to invite a larger number of PICUs in Italy and to include the parent satisfaction outcome data in the Italian PICU registry for benchmarking. The second limitation is that we did not evaluate the reproducibility of our results comparing two different cohorts in two different periods of time. This issue was investigated by Latour et al documenting that the comparison of two different cohorts did not reveal differences in the judgement of the PICUs and the opinion of the families (11). 
In conclusion, the translated and tested Italian EMPATHIC questionnaire has been proven to be a reliable and valid instrument measuring parent satisfaction of PICU services in Italy. The questionnaire and satisfaction outcome data provide a framework for quality improvement related to family-centered care issues. Furthermore, the Italian EMPATHIC questionnaire could be used for continuous or periodic audits and benchmarking the quality of PICUs based on the parent's views. The benefit of a validated Italian EMPATHIC questionnaire extends also to all PICUs across the world admitting children from Italian speaking families, particular in Europe with an increasing migration between countries.

\section{Acknowledgments}

We thank the parents to participate in the study and for their time to provide their valuable views and opinions.

\section{References}

1. Flaatten $\mathrm{H}$ : The present use of quality indicators in the intensive care unit. Acta Anaesthesiol Scand 2012;56:1078-1083.

2. Pronovost PJ, Berenholtz SM, Ngo K, et al: Developing and pilot testing quality indicators in the intensive care unit. J Crit Care 2003;18:145-155.

3. Dudley SK, Carr JM: Vigilance: the experience of parents staying at the bedside of hospitalized children. J Pediatr Nurs 2004;19:267-275

4. Hostler SL: Family-centered care. Pediatr Clin North Am. 1991;38:1545-1560

5. Kovacs PJ, Bellin MH, Fauri DP: Family-centered care: a resource for social work in end-oflife and palliative care. J Soc Work End Life Palliat Care. 2006;2(1):13-27

6. Levin AB, Fisher KR, Cato KD, et al: An Evaluation of Family-Centered Rounds in the PICU: Room for Improvement Suggested by Families and Providers. Pediatr Crit Care Med. 2015;16:801-807

7. October TW, Hinds PS, Wang J, et al: Parent Satisfaction With Communication Is Associated With Physician's Patient-Centered Communication Patterns During Family Conferences. Pediatr Crit Care Med. 2016;17:490-497

8. Sixma HJ, Kerssens JJ, Campen CV, et al: Quality of care from the patients' perspective: from theoretical concept to a new measuring instrument. Health Expect 1998;1:82-95

9. ten Asbroek AH, Arah OA, Geelhoed J, et al: Developing a national performance indicator framework for the Dutch health system. Int J Qual Health Care 2004;16:165-71

10. Pronovost PJ, Miller MR, Dorman T, et al: Developing and implementing measures of quality of care in the intensive care unit. Curr Opin Crit Care. 2001;7:297-303

11. Latour JM, van Goudoever JB, Duivenvoorden HB, et al: Construction and psychometric testing of the EMPATHIC questionnaire measuring parent satisfaction in the pediatric intensive care unit. Intensive Care Med 2011;37:310-318

12. Giannini A, Miccinesi G: Parental presence and visiting policies in Italian pediatric intensive care units: a national survey. Pediatr Crit Care Med 2011;12:e46-50 
13. Giannini A, Garrouste-Orgeas M, Latour JM: What's new in ICU visiting policies: can we continue to keep the doors closed? Intensive Care Med. 2014;40:730-733

14. Latour JM, van Goudoever JB, Elink Schuurman B, et al: A qualitative study exploring the experiences of parents of children admitted to seven Dutch pediatric intensive care units. Intensive Care Medicine 2011;37:319-325

15. Latour JM, van Goudoever JB, Duivenvoorden HJ, et al: Differences in the perceptions of parents and healthcare professionals on pediatric intensive care practices. Pediatric Critical Care Medicine 2011;12:e211-e215

16. Latour JM, van Goudoever JB, Duivenvoorden HJ, et al: Perceptions of parents on satisfaction with care in the paediatric intensive care unit: The EMPATHIC study. Intensive Care Medicine 2009;35:1082-1089

17. Wild D, Grove A, Martin M, et al: Principles of Good Practice for the Translation and Cultural Adaptation Process for Patient-Reported Outcomes (PRO) Measures: report of the ISPOR Task Force for Translation and Cultural Adaptation. Value Health 2005;8:94-104

18. Heyland DK, Rocker GM, Dodek PM, et al: Family satisfaction with care in the intensive care unit: results of a multiple center study. Crit Care Med 2002;30:1413-1418

19. Latour JM, Haines C: Families in the ICU: do we truly consider their needs, experiences and satisfaction? Nurs Crit Care 2007;12:173-174

20. Yu DS, Lee DT, Woo J: Issues and challenges of instrument translation. West J Nurs Res. 2004;26:307-20

21. Cortina J: What is coefficient alpha: an examination of theory and applications. Journal of applied psychology. 1993;78:98-104.

22. Gaudreault J, Carnevale FA: Should I stay or should I go? Parental struggles when witnessing resuscitative measures on another child in the pediatric intensive care unit. Pediatr Crit Care Med 2012;1:146-151.

23. Meyer EC, Sellers DE, Browning DM, et al: Difficult conversations: improving communication skills and relational abilities in health care. Pediatr Crit Care Med 2009;10:352359.

24. Fulbrook P, Latour J, Albarran J, et al: The presence of family members during cardiopulmonary resuscitation: European Federation of Critical Care Nursing Associations, European Society of Paediatric and Neonatal Intensive Care and European Society of Cardiology Council on Cardiovascular Nursing and Allied Professions joint position statement. Nurs Crit Care 2007;12:250-252.

25. Astuto M, Rosano G, Rizzo G, et al: Preoperative parental information and parents' presence at induction of anaesthesia. Minerva Anestesiol 2006;72:461-465.

26. Sitzia J, Wood N: Response rate in patient satisfaction research: an analysis of 210 published studies. Int J Qual Health Care 1998;10:311-317

27. Latour JM, Duivenvoorden HJ, Hazelzet JA, Tibboel D, and the EMPATHIC study group: The shortened EMPATHIC-30 questionnaire adequately measured parent satisfaction in pediatric intensive care units. J Clin Epidemiol 2013;66:1045-1050 